\title{
O Programa Bolsa Família Na Comunidade Ponte Dos Carvalhos/PE: Suas Implicações Políticas E O Que Está Sob O Manto Do Discurso
}

\section{The Bolsa Família Program Within The Community Ponte Dos Carvalhos/PE: Its Political Implications And What Is Under The Mantle Of Discourse}

\author{
Lizandra Kelly de Araújo Santana ${ }^{1}$, Débora Coutinho Paschoal Dourado ${ }^{2}$ \\ ${ }^{1}$ Faculdade Santa Helena, FSH, Brasil. ${ }^{2}$ Universidade Federal de Pernambuco, UFPE, Brasil. \\ Correspondência: Lizandra Kelly de Araújo Santana. Av. Caxangá, 990, Madalena CEP 50.711-070, Recife, PE, \\ Brasil. Telefone: +55 (81) 3797-6060. E-mail: lizandraaraujo.adm@gmail.com.
}

Recebido: 15 de outubro de 2018 Aceito: 27 de novembro de 2018 Publicado: 28 de dezembro de 2018

DOI: http://dx.doi.org/10.21714/1679-18272018v16n2.p194-206

\begin{abstract}
Resumo
A temática desenvolvimento vem sendo debatida no Brasil e na América Latina nas mais diversas esferas. Quanto a este tema, o presente trabalho se volta para a discussão da criação dos Programas de Transferência de Renda, em particular, do Programa Bolsa Família (PBF), inseridos no cenário de um novo modelo de desenvolvimento, denominado de neodesenvolvimentism, que vem sendo considerado para alguns autores, como uma política de desenvolvimento marcada por um aumento na precarização de trabalho no século XXI. Portanto, o estudo pretende trazer à tona o contexto que essas políticas redistributivas foram criadas, buscando entender quais são as funções políticas que o PBF exerce na comunidade Ponte dos Carvalhos, no município de Cabo de Santo Agostinho/PE.
\end{abstract}

Palavras-chave: Desenvolvimento, Trabalho, Programa bolsa família, Funções políticas.

\begin{abstract}
The thematic development is being debated in Brazil and in Latin America in the most diverse spheres. On this issue, the present work goes back to the discussion of the creation of Income Transfer Programs, in particular, the Bolsa Família Program (PBF), inserted in the scenario of a new development model, called neodesenvolvimentism, which is being considered for some authors, as a policy of development marked by an increase in the precariousness of work in the 21 st century. Therefore, the study intends to bring to the fore the context that these redistributive policies were created, seeking to understand what are the political functions that the PBF exerts in the Ponte dos Carvalhos, in the municipality of Cabo de Santo Agostinho/PE.
\end{abstract}

Keywords: Development, Work, Bolsa familia program, Political functions.

Esta obra está licenciada sob uma Licença Creative Commons Attribution 3.0.

\section{Introdução}

Guiados pelo discurso sobre a possibilidade de superação do subdesenvolvimento da América Latina, para responder ao novo quadro mundial de crise do capital que hoje se vive, desde o início dos anos 2000, os países da América Latina vivenciam o neodesenvolvimentismo, uma nova estratégia desenvolvimentista que está sendo apontada como uma alternativa de política de desenvolvimento que se propõe a promover crescimento econômico com justiça social.

De acordo com Mota, Amaral e Peruzzo (2012), nos anos 2000, os governantes ou candidatos que pleiteavam a representação dos chamados setores progressistas da sociedade chegam ao poder - no caso do Presidente do Brasil, em 2002, com Luiz Inácio Lula da Silva - com posicionamento anti-imperialista e a defesa do desenvolvimento nacional, compreendido como um meio de autonomia dos estados nacionais. Para os autores, não se tratava de uma repetição do desenvolvimentismo nacional dos anos 1960, mas da defesa de um desenvolvimento 
autossustentável desde o ponto de vista econômico e social.

Para Alves (2014), o neodesenvolvimentismo, na verdade, trata-se de uma nova visão de desenvolvimento capitalista baseado na criação de um novo patamar de acumulação de capital por meio da ação do Estado capaz de criar, por um lado, as condições macroeconômicas para o crescimento da economia capitalista e, por outro lado, ao mesmo tempo, a ampliação do mercado interno por meio da redução da pobreza e políticas sociais redistributivistas focadas no subproletariado.

O debate sobre Programas de Transferência de Renda vivencia uma abrangência e ampliação contemporânea mais precisamente a partir dos anos 1980. Trata-se de transformações geradoras de um profundo rearranjo do mercado capitalista, cuja maior manifestação são os processos de Globalização e Regionalização do Mercado, com concentração cada vez maior do capital, orientados pela internacionalização da economia, sob a hegemonia do capital financeiro. Daí decorrem situações que demandam ações do Estado para a proteção do amplo contingente de trabalhadores que passam a vivenciar o desemprego estrutural ou a precarização do seu trabalho, ampliando e disseminando a pobreza (SILVA; YAZBEK; GIOVANNI, 2001)

Foi nesse novo contexto político e econômico (o neodesenvolvimenismo) que se iniciaram as primeiras iniciativas dos governos latino-americanos relativas à redistribuição de renda, tendo como principais programas da América Latina, o Oportunidades do México (1997), o Familias em Acción da Colômbia (2001), O Bono de Desarrollo Humano do Equador (2003) e o Programa de distribuição de renda do Brasil, o Bolsa Família (2003).

A histórica e profunda concentração de renda decorrente dos modelos de desenvolvimento econômico adotados ao longo da construção do capitalismo industrial no Brasil, e sobre a exploração da força de trabalho vêm se aprofundando apesar da adoção de um conjunto amplo de programas sociais que são marcados por um caráter essencialmente compensatório, pouco contribuindo para amenizar as condições da pobreza de largo contingente da população brasileiro (SILVA, YAZBEK; GIOVANNI, 2011).

Diante disso, compreende-se que o perfil das famílias do Programa Bolsa Família indica que a opção do governo Lula foi a garantia de uma renda mínima a uma parcela da população do País. Porém, esta renda mínima não permite romper com as múltiplas expressões da desigualdade brasileira. Se de um lado, possibilita mesmo que de forma rebaixada, o acesso a uma renda, que por sua vez permite o consumo a alguns bens e serviços, de outro, mantém essas mesmas famílias em condições de vida muito precárias (SITCOVSKY, p. 193, 2010).

Portanto, o presente estudo pretende ressaltar a dimensão que o Programa Bolsa Família assume. Parte do pressuposto que o perfil das famílias elegíveis do Programa é composto por famílias que podem estar no mercado de trabalho formal, no entanto é detentor de uma renda familiar baixa, além de famílias que estão exercendo trabalho informal, por conta própria ou ainda aquelas que se encontram desempregadas. Logo, a princípio, podese considerar que o perfil de família elegíveis do PBF está inserido no contexto de precarização do trabalho. Com isso, o nosso problema está pautado em entender as funções políticas do PBF são exercidas na comunidade Ponte dos Carvalhos, compreendendo a dualidade existente no lócus escolhido, que por um lado reúne ao mesmo tempo o maior polo industrial de Pernambuco e por outro, há contingente de pessoas vivendo em situação de pobreza. Tal interesse nesta investigação parte do entendimento que o Programa pode cumprir funções políticas que, de acordo com Tavares e Sitcovsky (2012), acontece quando o PBF permite aos trabalhadores recusarem remunerações de miséria, historicamente pagas nas regiões mais pobres do país. Além disso, pretende-se discutir a possibilidade de o Programa poder gerar uma dependência social das famílias.

\section{Revisão da Literatura}

\subsection{O Trabalho Na Sociedade Capitalista}

Historicamente, a relação de trabalho representa a concretização da relação estabelecida entre o homem e a natureza para a satisfação de suas necessidades. Um processo contínuo onde o homem transforma a natureza em um determinado fim, a partir do que ele detém de mais valioso, a sua força de trabalho. Marx (2013) define força de trabalho ou capacidade de trabalho como o complexo das capacidades físicas e mentais que existem na corporeidade, na personalidade viva de um homem e que ele põe em movimento sempre que produz valores de uso de qualquer tipo.

O capitalismo é o único modo histórico de produção em que a força de trabalho é mercadoria. Aliás, é a transformação essencial da força de trabalho em mercadoria, através da instauração do trabalho livre, que nos dá a chave da acumulação de mais-valia. Sem trabalho livre ou força de trabalho como mercadoria, não existiria produção de mais-valia. Só a força de trabalho como mercadoria é capaz de produz mais-valia (ALVES, 2007).

O processo de trabalho no capitalismo se distingue do processo de trabalho em outras formas societárias précapitalistas. Neste sentido, a cooperação simples e a divisão manufatureira do trabalho, inseridas na evolução do processo de trabalho, ainda contribuem para o desenvolvimento das forças produtivas do trabalho social, não no 
sentido inicial, cujo trabalhador realizava suas atividades de forma autônoma, em sua própria oficina, mas, sendo agora controlada por um capitalista e organizado sob forma de cooperativa. Mas foi a introdução das máquinas, a partir da Revolução Industrial, que gerou novas significações aos elementos do processo de trabalho.

De acordo com Alves (2004), a partir da mundialização do capital, em meados dos anos 70 do século passado, surgiu a ideologia da globalização que na década seguinte tenderia a se disseminar pelo mundo capitalista. Em si, representava os interesses das corporações transnacionais e dos grandes fundos de investimentos privados, sedentos de uma valorização

Na visão de Carcanholo (2009), a partir da década de 1980, alguns ideólogos chegam a pensar até que o capital terminará não mais necessitando da força de trabalho para produzir riqueza e excedente, de maneira a garantir a rentabilidade exigida pelo capital. $\mathrm{O}$ trabalho teria, portanto, perdido centralidade; a tecnologia, a informação e o domínio do conhecimento foram alçados à categoria de entes mágicos capazes de tudo e objetos de adoração. Segundo o autor, do final da década de 1970 para cá, o capital financeiro, não só dominou o cenário capitalista, como superou os investimentos produtivos no que se refere à capacidade de apropriação de lucros, nessa época o capital se lançou na especulação e encontrou aí o remédio para a baixa rentabilidade que foi forçado a suportar durante a década de 1970. O desprezo pelo investimento produtivo e a busca avassaladora da rentabilidade liquida e segura, são os traços principais da natureza do capital financeiro. Ele floresce nos empreendimentos com papéis (ações, moedas e títulos públicos) que se disseminaram nos últimos vinte anos. É no bojo da mundialização financeira que se desenvolve o novo regime de acumulação flexível e com ele, um novo complexo de reestruturação produtiva, cujo momento predominante é um novo modelo produtivo, o toyotismo. Deste modo, no período de 1970-1980 deu-se início o processo de reestruturação econômica e reajuste social e político, pautado pela flexibilização dos processos e mercados de trabalho (HARVEY, 1992).

Harvey (1992) chamou de acumulação flexível esse novo padrão produtivo, de acordo com o autor, ela serve como pano de fundo para marcar a transformação da rigidez fordista para a flexibilidade dos processos de trabalhos, dos mercados de trabalho, dos produtos, dos padrões de consumo, da descontração industrial, da revisão do papel do Estado, da financeirização da economia, da heterogeneização e fragmentação da classe trabalhadora, da intensificação do trabalho, da precarização do trabalho. Além disso, a acumulação flexível parece implicar níveis altos de desemprego rápida destruição e construção de habilidades e o retrocesso do poder sindical.

A partir dessa reestruturação, que caminha em direção a desconstrução de muitas das relações trabalhistas estabelecidas em um período anterior, dá-se o processo de precarização do trabalho. Alves (2007) compreende que o processo de precarização do trabalho, que aparece sob a flexibilização do trabalho, impõe-se não apenas por meio da perda de direitos e do aumento da exploração da força de trabalho, por meio do alto grau de extração de sobretrabalho de contingentes operários e empregados da produção social. A precarização do trabalho se explicita por meio através do crescente contingente de trabalhadores desempregados supérfluos à produção do capital.

No contexto brasileiro, a precarização do trabalho assumiu na década de 2000, novas formas sociais, caracterizando-se, por um lado, pela precarização salarial, que se manifestou na persistência das altas taxas de rotatividade da força de trabalho, ou ainda, por disseminar novas formas de contrato de trabalho precário inscritas na Consolidação das Leis Trabalhistas - CLT. Por outro lado, a precarização existencial, decorrente do modo de vida just-in-time, que produz vida reduzida e provoca crescimentos radicais nas pessoas que trabalham, e precarização do homem-que-trabalha, decorrente de adoecimentos laborais, é o que afirma Alves (2014). O autor ainda acrescenta que foi nas condições do neodesenvolvimentismo no Brasil, que estas dimensões da precarização estrutural do trabalho se explicitaram plenamente, abordadas a seguir.

\subsection{Neodesenvolvimentismo e Dimensões da Precarização do Trabalho no Século XXI}

Na década de 2000, ocorreu a expansão e reorganização do capitalismo brasileiro com impactos cadentes no mercado de trabalho no Brasil. Com o novo padrão do desenvolvimento capitalista no Brasil, intitulado neodesenvolvimentismo, explicitou-se um novo (e precário) mundo do trabalho, em seu bojo, expõe os traços de uma nova precariedade salarial. O traço principal da nova condição salarial é seu caráter flexível (ALVES, 2014). A terceirização na década de 2000 assumiu o principal posto de geração de novas ocupações no Brasil. Entre 1995 e 2005, os postos de trabalho terceirizados formais foram os que mais cresceram no total da ocupação no país. O seu ritmo de expansão médio anual foi quase quatro vezes maior que as ocupações como um todo (ALVES, 2011; POCHMANN, 2008).

Com as flexibilizações do mercado de trabalho a força de trabalho se torna mais barata, pois se utilizam de trabalhadores contratados temporariamente e precariamente os quais num período de crescimento da economia são exauridos em longas jornadas para atender a níveis altíssimos de produtividade, para num momento de recessão, voltarem a condições de desempregados. E com o desemprego estrutural fica mais difícil de tais trabalhadores 
voltarem a ter empregos estáveis.

No caso do Brasil, Alves (2014) ressalta que existe uma flexibilidade estrutural do trabalho, que contribuiu historicamente para a vigência da superexploração da força de trabalho, modo histórico particular de consumo da força de trabalho no País. Por outro lado, ela decorre da oferta abundante de força de trabalho, que prolifera nas regiões metropolitanas permeada de ocupações informais e empregos ilegais.

No que diz respeito ao impacto deste projeto no mercado de trabalho brasileiro na década de 2000, Alves (2014) argumenta que é indiscutível que o seu impacto positivo (como por exemplo, com a redução da taxa de desemprego total e o crescimento da taxa de formalização no mercado de trabalho), diminuindo deste modo, a informalidade laboral. E são esses aspectos que o autor diferencia o neodesenvolvimentismo do neoliberalismo da década de 1990, marcado por uma dinâmica social do mercado de trabalho caracterizado pelas altas taxas de desemprego e crescimento da informalidade laboral. Entretanto, o autor assegura que, por outro lado, tivemos na década de 2000, a persistência dos traços da precariedade estrutural do mundo do trabalho no Brasil, com a alta rotatividade do trabalho e o crescimento dos contratos de trabalho precário por conta das novas modalidades de contratos flexíveis, inscritas na CLT como também com a expansão da terceirização e do emprego subcontratado.

Mota, Amaral e Peruzzo (2012) afirmam que é necessário ressaltar que a realidade dos novos padrões de desenvolvimentos da América Latina não indica possibilidades de êxito porque não tem sido possível manter o crescimento econômico com maior e melhor distribuição de riqueza. Para as autoras, mantém-se a concentração de riqueza e, na América Latina, em particular, constata-se que mais de $40 \%$ de sua população é pobre, persistindo as desigualdades sociais, porém, o que muda é a criação de outros meios de enfrentamento da pobreza através de políticas públicas de inclusão. Trata-se da expansão de políticas compensatórias, reconhecidas através dos chamados subsídios dirigidos aos mais pobres.

O novo padrão de desenvolvimento capitalista conduzido pela frente política neodesenvolvimentista, de modo evidente, conseguiu melhorar o padrão de vida de milhões de trabalhadores das camadas pobres do proletariado por meio de programas de transferência de renda. No entanto, para Alves (2014), apesar do glamour popular do neodesenvolvimentismo, existem dimensões ocultas da precarização do trabalho oriundas da nova precariedade salarial que expõem as misérias sociais do novo padrão de desenvolvimento capitalista no Brasil.

Segundo Boito Junior e Berringer (2013), é a "massa marginal", composta por subempregados, trabalhadores informais ou autônomos e desempregados, que forma a base de sustentação eleitoral do neodesenvolvimentismo. Para este grupo, a principal contrapartida é representada pelos Programas de Transferência de Renda, sendo o Programa Bolsa Família o maior e mais representativo dentre estes. Acredita-se que é justamente neste último grupo de interesse, alvo dos Programas de Transferência de Renda, onde se encontra a massa de trabalhadores mais vulneráveis à precarização do trabalho.

Tendo por base esta problemática, a seguir são apresentados os procedimentos metodológicos que nortearam o caminhar empírico deste trabalho. $\mathrm{O}$ grande farol para a trajetória foi responder ao proposto neste trabalho.

\section{Procedimentos Metodológicos}

Este estudo assume uma posição de cunho qualitativo, tendo como sua base ontológica a interação sujeito-objeto e sua epistemologia subjetivista. A relação com a realidade se deu por meio do paradigma interpretativo de investigação social, entende-se que paradigmas são acima de tudo, visões de mundo e não métodos de pesquisa. Com isso, o paradigma interpretativista parte do princípio que a realidade social não existe em termos concretos, mas é um produto de experiências subjetivas e intersubjetivas dos indivíduos (DENZIN; LINCOLN, 2005; SILVA; NETO, 2006).

Para a presente pesquisa adotou-se o estudo de caso como estratégia metodológica, uma vez que os estudos de casos são especialmente indicados na exploração de processos e comportamentos dos quais se tem uma compreensão limitada. Além disso, podem trazer uma importante contribuição quando a intenção do pesquisador não é explorar casos típicos, mas examinar casos extremos ou poucos usuais, os quais podem ser especialmente reveladores. Utiliza-se o estudo de caso quando o foco de interesse é sobre fenômenos atuais, que só poderão ser analisados dentro de algum contexto de vida real (GODOY, 1995; 2006).

Portanto, para a presente pesquisa o estudo de caso qualitativo é adequado por estarmos buscando entender a relação de um fenômeno atual, nesse caso, o Programa Bolsa Família - alvo de grandes críticas, de estudos nas mais diversas áreas - com a precarização do trabalho, a partir da interação com os atores sociais envolvidos com o Programa do lócus escolhido para tal estudo. O lócus desta pesquisa é uma Unidade de Desenvolvimento Humano - UDH localizado na microrregião de SUAPE, e pertencente ao município de Cabo de Santo Agostinho-PE, denominado Ponte dos Carvalhos. A escolha por este lócus é defendida por a Comunidade ter cerca de $70 \%$ das famílias como beneficiárias do PBF, ou seja, uma grande maioria da população em situação de vulnerabilidade 
socioeconômica, mesmo diante de a Comunidade situar-se na região circunvizinha ao polo econômico de SUAPE, o qual tem sua história marcada pela geração de empregos formais para esta região

Para alcançar o objetivo proposto pela pesquisa, foram utilizados dois tipos de coleta de dados, a observação participante, vivência no locus e entrevista qualitativa, semiestruturada e não estruturada propiciadas pela convivência dos pesquisadores com o lócus e sua comunidade. Deve-se acrescer que o grupo de pesquisa já vem desenvolvendo outros projetos de pesquisa na comunidade, fato que facilitou a imersão na mesma. Segundo Godoi e Mattos (2006), a entrevista qualitativa é um construto comunicativo, uma forma de produção e interpretação de informação através da análise dos discursos, e não um simples registro do que falam os sujeitos. Assim, foram entrevistadas 9 (nove) beneficiárias do PBF. Adotou-se a construção de um protocolo de entrevista que, inicialmente, para que as beneficiárias contassem como era sua vida na comunidade em que vive, afim de deixálas à vontade e confiantes no contar. Com isso, ao adentrar em questões sobre o PBF, buscou-se fazê-las perceber que o momento da "conversa" era para lhes dar voz sobre questões até então obscurecidas.

Após a etapa de coleta dos dados, partiu-se para análise e interpretação dos dados. Vale salientar que esta etapa, preferencialmente, aconteceu em paralelo à coleta, tendo em vista que ao final de cada entrevista, acompanhada da observação, observava-se uma riqueza de informações e detalhes, que ao decidir analisá-las no final do processo, correríamos o risco de perder o real significado, a visão subjetiva, as crenças e valores transmitidos pelos entrevistados no momento da coleta. Para tal, optamos pela Análise Pragmática de Conversação. Segundo Myers (2002), o foco da análise de conversação é o ato da fala, na interação entre os interlocutores ou naquilo que ocorre enquanto se fala. Como forma de sugestão a alternativas metodológicas, no caso da técnica de análise denominada por análise pragmática de conversação, Mattos (2005) propõe cinco fases que o pesquisador precisará seguir para $\mathrm{o}$ aprofundamento da análise dos significados produzidos em uma entrevista: recuperação, análise do significado pragmático da conversação, validação, montagem da consolidação das falas e análise dos conjuntos.

Terminada a etapa de coleta, deu-se início a primeira fase da análise, a de recuperação, proposta por Mattos (2005), quando todas as entrevistas foram transcritas na íntegra. Como essas transcrições foram realizadas imediatamente foi possível, ao ouvir todas as gravações, lembrar de todos os momentos da conversa, incluindo fisionomias e os gestos das beneficiárias.

Terminada essa fase, partiu-se para a segunda, análise do significado pragmático da conversação, como o autor ressalta, com o interesse de observar como se desenrolou o contexto pragmático do diálogo. No caso do presente estudo, foi possível perceber no primeiro dia de coleta, realizada na própria comunidade, mais especificamente, realizada na casa de uma delas, com o apoio de uma agente do CRAS, que com a presença dela, as beneficiárias se sentiam um pouco mais retraídas a nos repassar suas informações. No entanto, em outros momentos, sem essa presença, elas foram compartilhando mais suas impressões acerca do objeto. Quanto aos assuntos, foi possível perceber que em relação a sua vivência na comunidade, além das mudanças na sua rotina oriundas do Bolsa Família, elas eram mais abertas e detalhistas, porém, quando eram inseridas as conversas sobre seus traalhos, algumas ficavam mais contidas. Desta constatação, depreendeu-se que o que estava por trás era o receio de, ao assumir que trabalhavam, poderiam as respondentes perder o auxílio relativo ao PBF. Cabe destacar aqui que o nosso instrumento de coleta foi construído a partir de indagações primárias, dando a liberdade de eles falarem livremente, e indagações secundárias, caso algumas questões fossem julgadas importantes aprofundar. Entretanto, na maioria dessas conversas, todas as questões de nosso interesse foram contempladas com a primeira parte da entrevista, a não-estruturada. As demais serviram de aprofundamento e manutenção de uma relação de confiança entre as partes. Ao total, as nove entrevistas foram suficientes para saturação das questões originalmente propostas.Por se tratar de uma abordagem subjetivista, torna-se ainda mais necessário preservar todas as informações colhidas no momento da coleta, e é nessa fase que entra a validação, essa fase 3 , defendida por Mattos (2005), que não diz respeito a validação muitas vezes inata da pesquisa quantitativa, nesse caso, diz respeito a, ao entrevistar as famílias beneficiárias do Programa e ao mesmo tempo que iam surgindo algumas interpretações iniciais, foi questionado se de fato o que entendido, no primeiro momento, era mesmo aquilo.

Como sugerido por Mattos (2005), a fase 4, montagem da consolidação das falas, foi realizada como forma de contribuir para uma melhor análise dos dados. Partiu-se do instrumento de coleta, que para cada pergunta elaborada foram relacionados os objetivos específicos da pesquisa. Em seguida, seguiram-se todos os passos sugeridos pelo autor: primeiro, separaram-se todas as perguntas realizadas; segundo, distinguiram-se as entrevistadas e os demais tipos de dados complementares, de forma que questões semelhantes fossem agrupadas; e, terceiro, foram recortados os trechos que considerados como mais significativos para a pesquisa.

A quinta e última fase do modelo para análise pragmática de conversação, denominada de análise dos conjuntos, foi realizada a partir da organização e separação dos trechos agrupados na fase 4 . Como o autor do proposto modelo, não especifica como a análise deve ser feita (como por exemplo, se com a utilização ou não de categorias 
analíticas) essa pesquisa optou por adotar as categorias analíticas a partir dos temas emergidos do conteúdo coletado, além relacioná-los com categorias extraídas do referencial teórico. Com isso, fragmentamos a seção de análise a partir dos tópicos: Lócus de Pesquisa: A comunidade Ponte dos Carvalhos e Precarização do Trabalho e as implicações políticas do PBF.

\section{Análise E Discussão Dos Resultados}

\subsection{Lócus De Pesquisa: A Comunidade Ponte Dos Carvalhos}

O lócus desta pesquisa é uma Unidade de Desenvolvimento Humano - UDH localizado na microrregião de SUAPE, e pertencente ao município de Cabo de Santo Agostinho-PE, cidade ao sul da capital do estado. De acordo com Rios et al (2015), o município compõe uma das primeiras regiões de povoamento no Brasil, que, até muito recentemente, teve sua economia centrada na produção de cana-de-açúcar, ainda apresentando fortes marcas da cultura escravocrata, que se expressam significativamente na permanência das desigualdades sociais. Além disso, os autores destacam que durante o regime militar, o município do Cabo de Santo Agostinho recebeu altos investimentos públicos, por meio da Superintendência do Desenvolvimento do Nordeste (Sudene), para o desenvolvimento de um polo industrial que funcionou relativamente bem até o início dos anos 1980, vindo a reduzir substancialmente suas atividades até meados dos anos 1990, quando foi paulatinamente reativado. Hoje essa região reúne ao mesmo tempo o maior polo industrial de Pernambuco. O Complexo Industrial e Portuário de Suape favoreceu o surgimento de um parque industrial a seu redor, que hoje conta mais de 50 empresas, gerando cerca de 4 mil empregos diretos e 20 mil indiretos.

O Cabo de Santo Agostinho teve seu desenvolvimento impulsionado com o Complexo Industrial e Portuário de Suape, que é um projeto com mais de três décadas de planejamento no estado de Pernambuco. A fase de implantação intensiva do complexo foi iniciada em 2007. O site do Complexo9 veicula informações sobre a vocação e a dinamicidade do projeto. Informa que Suape abarca, além do porto em si, o "maior estaleiro do hemisfério Sul", uma refinaria de petróleo, três plantas petroquímicas, mais de 100 empresas já instaladas e ainda tem previsão de instalação de pelo menos 50 novas indústrias. Os promotores do Complexo ressaltam que Suape se insere em uma vocação histórica de comércio estabelecida desde a descoberta do Brasil, remontando à criação de um mito de origem nacional de comércio internacional (QUEIROZ et al, 2015).

Em Ponte dos Carvalhos, a população estimada era de 19.000 habitantes de acordo com o último censo demográfico, desses, $5,7 \%$ correspondia ao percentual referente à população extremamente pobre, enquanto $24,4 \%$ era referente à população pobre do bairro. Outros dados que chamam atenção dizem respeito ao percentual de mães chefes de família sem fundamental e com filho menor, o que ultrapassava $50 \%$ da população e ao percentual de pessoas de 18 anos ou mais sem fundamental completo e em ocupação informal, o que correspondia a $41 \%$ da população, resultando em um percentual de $56 \%$ da população vulnerável à pobreza.

A escolha por este lócus é justificada pelo fato da Comunidade ter cerca de $70 \%$ das famílias como beneficiárias do PBF, ou seja, uma grande maioria da população em situação de vulnerabilidade socioeconômica, mesmo diante de a Comunidade situar-se na região circunvizinha ao polo econômico de SUAPE, o qual tem sua história marcada pela geração de empregos formais para esta região.

\subsection{Precarização Do Trabalho E As Implicações Políticas Do Pbf}

Na visão de Sitcovsky (2010), o crescimento da pobreza em decorrência da própria lógica capitalista e da precarização do trabalho, são mediações para o desenvolvimento de programas sociais de renda mínima como o Bolsa Família. O autor destaca também que o trabalho e a informalidade fazem parte das estratégias para rebaixar os custos da força de trabalho, e que nesse sentido, a articulação de trabalho precário e estes programas de renda mínima desempenha esta mesma função, a de rebaixar os custos da força de trabalho. A pesquisa de campo revelou casos típicos de trabalhadores precários entre os beneficiários do Bolsa Família, tal como podemos ilustrar com as falas que seguem:

\footnotetext{
Rapaz, eu corro atrás de emprego, fichado. Porque eu tendo aquele dinheiro fichado ainda posso ajudar minha mãe, porque eles só vivem com ela e ficam aperreando. Eu boto currículo em todo canto, mas nunca fui chamada. Queria muito trabalhar, mas se fosse fichado, clandestino tem futuro não. Porque se eu for trabalhar na praia, é R \$50,00 o dia, eu deixo os meus meninos, aí pronto, não vale muito coisa, porque eu tenho que dar $\mathrm{R} \$ 50,00$ a pessoa que fica com eles. Hoje ninguém paga mais que $\mathrm{R} \$ 50,00$ e a pessoa trabalha que nem um escravo. Só trabalha até 18:00 da noite se for pra trabalhar em bar. É muito arriscado, uma panela daquela de caldinho, óleo quente cair em cima da pessoa, não é fácil não (Entrevistada 1).
}

Eu trabalhava fichada, mas vai fazer uns 4 anos que eu não estou trabalhando. Agora quando aparece uma diária para fazer, eu vou e faço, ai ganho 70,00, 80,00. Eu quero trabalhar com qualquer coisa, até no lixão, que eu já trabalhei (Entrevistada 2).

Nunca trabalhei de carteira de assinada. Trabalhava costurando fronha e lençol (Entrevistada 3). 
Aí a gente tem que buscar algo fora, faz uma lavagem de roupa, uma faxinazinha, aí ganha o quê? Muitos pagam $\mathrm{R} \$ 50,00$, pagam $\mathrm{R} \$ 40,00$ (Entrevistada 5).

No que concerne à inserção dos pobres no mercado de trabalho, percebe-se também nos depoimentos destacados acima, que há uma relação do Bolsa Família com a reprodução daquilo que Marx (2013) denominou de superpopulação relativa do tipo flutuante e estagnada. Para compreender este fenômeno, faz-se necessário contextualizar a crítica que o autor faz em O Capital, quando afirma que a superpopulação relativa, ou seja, ' 'uma população trabalhadora adicional, excedente, isto é, excessiva para as necessidades médias de valorização do capital e, portanto, supérfluas", assume três formas: flutuante, latente e estagnada. A flutuante corresponde à força de trabalho que ora é repelida ora é atraída de acordo com as alterações das composições orgânicas do capital. A latente corresponde aos trabalhadores rurais rebaixados ao mínimo da sobrevivência. A superpopulação relativa estagnada forma uma parte do exército ativo de trabalhadores, mas com ocupação totalmente irregular. Suas características são o máximo de tempo de trabalho e o mínimo de trabalho.

No caso dos trabalhadores sem carteira assinada e autônomos, pode-se perceber que a precarização de trabalho se dá através das relações de trabalho informal. Para Sitcovsky (2010) como o auxílio do Bolsa Família não se constitui um direito, a situação desse contingente de trabalhadores é ainda pior, pois se o benefício por qualquer razão, inclusive orçamentária for cortado, o trabalhador fica sem nenhuma outra forma de proteção social.

A condição de precariedade das relações de trabalho dos beneficiários impostas pela informalidade, resultando em incertezas constantes sobre a existência do trabalho, em baixíssimas rendas e em vulnerabilidade social, destaca a relevância de políticas públicas mais efetivas voltadas ao incentivo à regularização das relações de trabalho e garantias de direitos trabalhistas para os beneficiários e ao acesso ao trabalho formal.

De fato, o desemprego é, na sociedade de mercado, um fator de risco para as condições de vida ou para a reprodução social. Todavia, a ocupação precária não é a resolução ao desemprego. A permanência da incerteza no sustento não permite o horizonte de sustentabilidade e, com isso, a desproteção. A proteção social não é resolvida pelo mercado de trabalho, ainda que, ter salário e renda amplie as condições da família realizar sua reprodução social e de seus membros, em quantidade e qualidade mais significativa ressalvando-se sempre que, este significado depende da cobertura que o valor do salário proporciona face ao poder de compra no mercado (SPOSATI, 2009).

A pesquisa de campo também foi capaz de indicar que as possibilidades de geração de renda frequentes nesse contexto são via trabalhos esporádicos (faxinas e pequenos serviços) e os domésticos (artesanatos). Além disso, a falta da formalidade de trabalho via carteira assinada, por exemplo, também foi comentada como episódio na vida das pessoas e não como regularidade. Desta maneira, demonstraram a vulnerabilidade relativa ao emprego a que estavam submetidos.

Por conta disso, para a grande parte das entrevistadas, o PBF se tornou o único elemento de proteção social destas famílias. Ausentes de segurança e estabilidade em suas relações de trabalho, muitos beneficiários têm o benefício como garantia de necessidades básicas, tais como alimentação e moradia. Neste sentido, o PBF é um amenizador de muitas das situações de insegurança, seja irregularidade no trabalho, impossibilidade de trabalhar por questões de saúde, ou a ausência de um cônjuge na criação dos filhos, como descritos nos seguintes relatos:

Olha, eu procuro mas não encontro. Eu queria trabalhar mas não posso porque minha menina de 14 anos engravidou, aí eu fico com meu neto para ela estudar. No momento meu marido não trabalha, está desempregado há três anos, faz bico por aí e eu tenho a renda do bolsa família. Recebo R \$202,00. Antes do benefício eu trabalhava, mas não pude trabalhar mais por causa do meu neto. Mas eu agradeço, esse benefício é uma grande ajuda [...] Minha filha mãe desse meu neto gosta de estudar, por isso que eu fico com ele pra ela estudar. Porque já que eu não pude terminar, eu quero que ela termine. Aí por isso que eu não trabalho, porque fico com meu neto (Entrevistada 7).

Esse depoimento acima nos ajuda a entender alguns fatores que contribuem para a relevância do PBF quanto ao sustento das famílias. Por exemplo, um fator a destacar refere-se à centralidade da mulher no tocante à subsistência da família, uma vez que, nesse caso, ela tem que desempenhar diversos papéis, seja pelo desemprego do marido e pelo exercício do trabalho informal. Ela contou que o seu cônjuge, no momento da entrevista, fazia " bicos", por conta de dificuldade de acesso ao emprego, tanto pela falta de oportunidade mencionada, quanto pela impossibilidade familiar, uma vez que ela precisa cuidar do neto para que sua filha, menor de idade, possa estudar (cuja freqüência escolar é uma condicionalidade para recebimento do PBF).

Trabalhei em um colégio, aí ele fechou. Eu ajudava minha cunhada na secretaria, não era carteira assinada. Depois que saí desse trabalho não consegui mais não. Porque eu tenho minhas " benças", aí com minha sogra doente eu vou deixar com quem? Agora não tem como eu trabalhar, só quando meu pequeninho crescer mais, porque ele tem 6 anos, mulher e, é muito levado. Porque também não compensa se eu for trabalhar pra ganhar um salário mínimo e arrumar 
uma pessoa pra ficar com ele, eu não vou ficar com nada, porque ninguém vai querer ficar com menino dos outros de graça, minha sogra é doente e também entendo o lado dela, eu não vou pegar uma criança pra deixar com uma pessoa que não tem condições, tenho que ter consciência. E o filho é meu, quem tem obrigação sou eu, não é ela não (Entrevistada 8).

Neste segundo depoimento, além de ser possível perceber também a centralidade do papel da mulher, identificase ausência de serviços sociais do Estado que possam complementar a ajuda financeira, tanto pela dificuldade de acesso ao emprego ou até mesmo a ausência de creches e escolas para que estas mães possam deixar seus filhos e, com isso, terem condições de ir em busca de emprego. Neste sentido, destaca-se que para que o alcance do benefício possa ser atingido é necessário que seja oferecido outros meios de superação da sua condição de pobreza.

O Programa Bolsa Família recebe inúmeras críticas por fomentar um "efeito preguiça” entre seus beneficiários, estas críticas ressaltam ser um programa capaz de gerar uma dependência social para com as famílias beneficiárias. Ao acostumar as pessoas a viverem da assistência do Estado, o PBF as induziria a se empenharem menos na superação da pobreza pelos seus próprios meios, e levaria ao aprofundamento, no longo prazo, da própria pobreza no país (SOARES e SATYRO, 2009). Contudo, é preciso analisar cuidadosamente esta compreensão lançando dúvidas sobre ela, pois de acordo com os dados coletados, quando levantadas questões se estas famílias rejeitaram algum tipo de trabalho após o recebimento do benefício, foi possível perceber nos discursos argumentos contrários e até aversivos a isso, conforme pode ser ilustrado abaixo:

Olhe, fia, eu vou dizer uma coisa a você, eu trabalhava em engenho, cortando cana, semeando adubo, esses negócios de engenho, aí foi no tempo que eu me juntei com um membro da família, nesse negócio da indenização das casas aí ele não deixou eu trabalhar mais, porque eu sentia muita dor nas pernas, aí através disso eu me cadastrei no BF, eu não tenho nada o que dizer do benefício, porque eu tinha um trabalho antes muito cansativo, a gente que trabalha em engenho leva: sol, chuva, sereno. A gente sai de madrugada para trabalhar, tinha dia que a gente chegava em casa de 16:00 da tarde, muito cansada.

\section{$[\ldots]$}

Acho que se eu tivesse continuado trabalhando, eu já estava no benefício, aposentada, porque era muitas dores nas minhas pernas. Eu vou fazer 50 anos, mas desde os meus 39, 40 anos que eu sinto dor. Acho que se eu não entrasse no benefício ou não me aposentasse por invalidez, eu iria passar necessidade, porque eu não ia aguentar trabalhar mais não. Você não é de engenho, você pode não entender. E só ganhava se tirasse as canas, se não tirasse, a gente não ganhava. Aí voltava a tarde ou no outro dia, para tirar o resto. Então eu acho que hoje eu não aguento mais (Entrevistada 5)

Nesta fala acima o que se percebe não é a figura de alguém que se sente "acomodada" com o benefício ou que não queira trabalhar, percebe-se um discurso de uma beneficiária que dedicou sua vida a um trabalho degradante, cansativo e com índice elevado de exploração laboral, nesse caso, exercendo a função de cortadora de cana. Como consequência disso, sua saúde foi afetada, encontrando-se muitas vezes incapacitada de realizar algum tipo de trabalho. Logo, a partir do depoimento desta entrevistada é possível perceber a importância do benefício para estas famílias.

Sabe-se que o histórico das condições de trabalho nos canaviais é considerado degradante, uma das críticas mais contundentes ao corte manual de cana-de-açúcar diz respeito ao pagamento por produtividade, ou seja, o que determina quanto cada um receberá é a quantidade (em toneladas) de cana cortada diariamente: quanto maior a produção, maior o salário. Esse tipo de pagamento tem por objetivo a produtividade crescente, fazendo com que os trabalhadores aumentem o esforço dispendido no trabalho, o que pode provocar sérios problemas de saúde (dores no corpo, câimbras, falta de ar, desmaios etc) para o trabalhador ou até mesmo a morte dentro e fora dos canaviais.

Para Alves (2010) o trabalhador, quando recebe por produção, tem o seu pagamento atrelado ao que ele conseguiu produzir no dia. Como eles trabalham pela subsistência, trabalham cada vez mais para melhorar suas condições de vida, isso provoca o aumento do ritmo de trabalho. O pagamento por produção transfere ao trabalhador a responsabilidade pelo ritmo do trabalho, que é atribuição do capitalista. O desgaste de energia neste tipo de função enorme: andando, golpeando, agachando-se, carregando peso, além das vestimentas, como detalhados pela entrevistada 5 no seguinte trecho:

A gente usava aquelas perneiras de couro até o joelho, calças, camisa comprida, luvas, lenço no rosto e pescoço, chapéu ou boné, debaixo de sol ou chuva.

Essas condições de trabalho descritas contribuem para que os trabalhadores na atividade sejam expostos ao calor em demasia, podendo levar à desidratação e a conseqüentes problemas de saúde agravados pelo pelo ritmo de produção intenso a que são submetidos.

Durante um bom período, a entrevistada 5 esteve inserida numa relação de trabalho em que não havia também distinção entre local de trabalho e local de moradia. Durante o trabalho estava exposta a chuva e sol para que 
pudesse ganhar o seu sustento, muitas vezes apenas para o atendimento de suas necessidades básicas. Se a intenção era receber um pouco a mais, era preciso submeter-se a uma jornada de trabalho excessiva, como visto no depoimento, muitas vezes saía de casa pela madrugada e só retornando ao findar do dia.

Conforme argumentou Marini (2000), a exigência de mais-trabalho, mediante procedimentos extensivos ou intensivos, ao provocar fadiga e esgotamento, resulta no incremento do que Marx chamou 'as pestes de guerra do exército industrial, que têm nos acidentes de trabalho um de seus indicadores mais representativos. Logo, o prolongamento da jornada de trabalho além da jornada normal constitui um aumento da exploração extensiva do trabalhador (LUCE, 2012).

Além disso, identifica-se, nesse discurso aquilo que Alves (2014) já vem problematizando em seus estudos sobre a precarização do trabalho no capitalismo histórico. De um lado, percebe-se uma a precariedade salarial extrema, "os trabalhadores assalariados não eram sujeitos de direito. A indústria era o polo da brutalidade salarial, onde vigorava o trabalho degradante, trabalho por extensas jornadas de trabalho com remuneração abaixo da linha de subsistência", isso é ilustrado quando a entrevistada afirma que, quanto à remuneração, só "ganhava quando tirasse as canas, quando não, não ganhava", além disso, cumpriam uma extensa jornada de trabalho. De outro, identifica-se também a precarização do homem-que-trabalha/precarização existencial, tal geração "emergiu no bojo da nova precariedade salarial flexível, que não se reduz à corrosão do estatuto salarial, mas sim, que diz respeito à precarização do homem que como ser genérico e precarização das condições de existência humana". Por fim, fica evidente no discurso, a precarização do trabalho no contexto brasileiro assumida na década de 2000, denominada por Alves (2014) como a precarização existencial, decorrente do modo de vida just-in-time, que produz vida reduzida e provoca crescimentos radicais nas pessoas que trabalham, e precarização do homem-quetrabalha, decorrente de adoecimentos laborais.

Logo, pode-se considerar que nesse contexto o PBF vem exercendo aquilo que Sitcovsky (2010) definiu como função política do mesmo, no sentido de que, embora, consideremos um valor insuficiente para tirá-la da pobreza, permite que a mesma recuse trabalhos que novamente possam submetê-la a uma exploração, ou seja, trabalhos que ponham em risco a sua condição humana. Neste caso específico fica claro que a entrevistada 5 vive apenas do Bolsa Família, no entanto, esta condição não é suficiente para argumentar que o programa tenha gerado uma dependência, pois percebe-se também que atualmente essa mesma entrevistada e beneficiária encontra-se impossibilitada de exercer algum tipo serviço que exija a sua força de trabalho.

Somando-se a esta discussão, destaca-se também um outro discurso que problematiza essa ideia de que o bolsa família exerce função política, porém no sentido de possibilitar uma dependência social:

O BF é só uma ajuda. Quem vai deixar de querer receber um salário para ganhar 300,00 por mês só? Você sabendo que pode ir ali numa firma receber uma quinzena, um plano de saúde, uma cesta básica pros seus filhos, por causa de 300,00 real? Eu mesmo não. Eu não trabalho porque dei entrada no INSS, por causa dessa lesão na minha vista, por isso que eu não trabalho (Entrevistada 3).

Aqui mais uma vez é fortalecida a ideia de que o PBF é considerado por essas famílias apenas como uma ajuda, embora necessária e única renda par algumas. Percebe-se o desejo de que possam ser inserida no mercado de trabalho formal, para assim poder usufruir de alguns direitos que hoje são inalcançáveis.

De acordo com os dados coletados, identificou-se outras situações que contribuem para que as famílias recebam o auxílio e não estejam inseridas no mercado de trabalho, mais uma vez, tais situações reforçam a ideia de um cuidado maior ao afirmar a relação do programa e o "efeito preguiça", conforme pode-se ilustra a seguir:

Se eu mesmo arranjasse um emprego, eu passaria o meu BF para alguém que tivesse precisando mais do que eu. Eu gosto de trabalhar, até ontem eu tava falando para menina arrumar para mim numa casa de família. Mas geralmente aparece mais para dormir, eu não posso sair e deixar ela só (Entrevistada 2).

Até hoje mesmo eu quero trabalhar, já trabalhei já, mas a firma que eu trabalhava fechou. Eu quero trabalhar, mas não consigo, tá difícil. Eu trabalhava com banheiro químico, porque era pra refinaria. Lavando banheiro químico. Eu só não trabalho porque não encontro oportunidade, nenhuma porta aberta (Entrevistada 4).

Não, eu não trabalho. Meu marido faz bico, vai se virando. Às vezes pesca. Quando não tem, vai se virando, só sou eu e ele dentro de casa mesmo. Aí o que aparece dá, não dá quando tem muita gente, e assim mesmo ainda dá, porque Deus dá um jeitinho de acontecer. Não achei oportunidade de trabalhar aqui, só trabalhei com carteira assinada há muito tempo e passei só dois meses. Ai recebo R\$ 85,00 do Bolsa Família (Entrevistada 6).

O meu BF já cancelou uma vez, passei 5 meses sem receber, aí vim no CRAS, ela ajeitou meus documentos e com dois meses começou a sair de novo. Aí nesse tempo eu fazia faxina pra me virar. Eu nunca deixei de trabalhar porque recebo o Bolsa Família, como disse a você, faço meus bordados, meus crochês, já pra ajudar. O dinheiro do meu Bolsa Família já dá pra comprar minhas coisas (Entrevistada 8). 
Emprego tá difícil. Meus filhos estão desempregados, eu cuidadora estou desemprega, tenho o curso e estou desempregada, estou há três anos. É ruim, a gente acostumada a trabalhar. Eu trabalhei muito tempo, de limpeza, de bábá, de doméstica, já trabalhei na prefeitura, agora a prefeitura dá um benefício de $\mathrm{R} \$ 250,00$ de um projeto chamado onda limpa, que é pra gente estudar. Eu tentei trabalhar, mas é difícil, até pra pessoa comprar uma coisa e ficar vendendo, não tem renda pra isso. Lutei que só pra empresa Locar, de limpeza, uma terceirizada, mas não consegui nada, Um salário pra limpar esgoto, varrer rua, limpar mato e não consegui. Eu ando demais menina com meu filho atrás de emprego, currículo aqui, currículo ali (Entrevistada 9).

A partir de cada depoimento é possível identificar que as beneficiárias encontram em condições precárias de trabalho, tendo em vista que no relato mais uma vez é destacada a dificuldade de acesso ao mercado de trabalho formal, até mesmo por não possuírem a mínima qualificação exigida, considerando que estas famílias não encontram oportunidade de trabalho uma vez que a maioria não possui sequer o ensino básico, ficando mais uma vez sujeitas à informalidade para complementar sua renda familiar.

Como se sabe, o recebimento do Bolsa Família é condicionado ao cumprimento por parte dos beneficiários de algumas contrapartidas, como na saúde e educação, e por exemplo, uma das críticas em condicionar esse benefício a educação, vai ao encontro com o que argumentam Silva, Yasbek e Giovanni (2011), de que a obrigatoriedade à escola não é suficiente para alterar o quadro educacional das futuras gerações e, consequentemente, alterar a pobreza. Para eles, essa exigência implica na expansão, na democratização e na melhoria dos sistemas educacionais estaduais e municipais. Nesta mesma linha, no que diz respeito à necessidade de uma rede ou integração de políticas públicas, uma vez que isolado o Bolsa Família não é capaz de alterar o quadro atual da educação e saúde, insere-se também a discussão sobre trabalho a estes três discursos acima, ou seja, para que as famílias consigam se inserir no mercado de trabalho e rechaçar tal ideia de que o BF gera uma dependência social, é necessário que estas mesmas famílias encontrem oportunidade para sua inserção. Por sua vez, quando não encontram, importância deste benefício para que estas famílias consigam muitas vezes sair de uma situação de miséria torna-se ainda mais revelada.

Silva (2007) defende que as condicionalidades definidas pelos Programas de Transferência de Renda, no caso do PBF, condicionalidades voltadas a Saúde, Educação e Assistência Social pareçam pretender garantir acesso a direitos sociais básicos no sentido de potencializar impactos positivos sobre a autonomização das famílias atendidas.

Mesmo assim, apresentam problemas e desafios a serem considerados. Para a autor, primeiro, ferem o princípio da não condicionalidade peculiar ao direito de todo cidadão a ter acesso ao trabalho e a programas sociais que lhe garantam uma vida com dignidade; segundo, os serviços sociais básicos oferecidos pela grande maioria dos municípios brasileiros, mesmo no campo da educação, da saúde e do trabalho são insuficientes, quantitativa e qualitativamente, para atender às necessidades das famílias beneficiárias dos Programas de Transferência de Renda. Nesse sentido, as condicionalidades deveriam ser impostas ao Estado, nos seus três níveis e não às famílias, visto que implicam e demandam a expansão e a democratização de serviços sociais básicos de boa qualidade, que uma vez disponíveis seriam utilizados por todos, sem necessidade de imposição e obrigatoriedade. Concomitante, poderiam ser desenvolvidas ações educativas, de orientação, encaminhamento e acompanhamento das famílias para a adequada utilização dos serviços disponíveis.

O que se tem observado é que a questão das condicionalidades provoca enormes controvérsias no debate sobre programas de transferências de renda. Em alguns casos, elas acabam atuando como instrumentos para garantir alguns direitos básicos, especialmente nas áreas de saúde e educação. Nestes casos, as condicionalidades são vistas como elementos positivos, uma vez que certos requerimentos, como é o caso frequencia regular às escolas, além de membros adultos das famílias beneficiárias terem de participar de atividades de qualificação, poderão aumentar a formação de capital humano.Contudo, em outros casos, a simples existência de condicionalidades acaba excluindo pessoas e localidades da assistência dos programas, tendo em vista as diferentes condições de acesso aos serviços ofertados (MATTEI, 2015).

A grande maioria destas líderes de famílias que contribuíram para nossa pesquisa, não tem sequer o ensino básico, ou seja, elas não possuem o critério mínimo para que sejam inseridas no mercado de trabalho formal. Ficando sujeitas a absorção do mercado de trabalho precário, seja ele informal e/ou terceirizado e com isso, excluídas de qualquer proteção trabalhista. Outro destaque refere-se ao lócus que essas famílias estão inseridas. O Cabo de Santo Agostinho teve seu desenvolvimento impulsionado pelo Complexo Industrial e Portuário de Suape, considerado um dos principais polos de investimento do país, "maior estaleiro do hemisfério Sul", que conta com mais de 100 empresas em operação, ainda tem previsão de instalação de pelo menos 50 novas indústrias e responsável por cerca de 25 mil empregos diretos. Neste caso particular, têm-se o argumento de que foi possível gerar inúmeros empregos com essa instalação, entretanto, estas duas entrevistadas revelam que: 
O Porto gerou muito emprego, mas agora muita gente desempregada. Minha filha, tem metalúrgico e soldador varrendo rua, nessa terceirizada. Metalúrgico e soldador, pra você ver! (Entrevistada 9).

Depois de Suape ficou difícil, antes era melhor. Quando tinha o estaleiro, mas agora é muita gente desempregado. Antes tinha uma fábrica de colchão em Prazeres, mas depois do Porto fechou, aí muita gente ficou desempregada. No Porto de Suape tem mais gente de fora, Bahia. Lá na rua onde moro tem umas 5 pessoas de lá, mas também estão desempregados (Entrevistada 8).

Ou seja, muitas pessoas do próprio lócus não conseguem esta inserção, por conta do baixo nível de formação dessa população sem que se tenha realizado nenhuma iniciativa para incluir estas famílias neste novo mercado de trabalho. Ao contrário, o que se percebe foi um movimento migratório de inúmeras pessoas de outras localidades, até mesmo outros estados, como pode ser observado na fala da oitava entrevistada. Assim, toda essa discussão sobre o chamado "efeito preguiça" precisa ser feita de forma profunda e qualificada, além do que está posto no senso comum, uma vez as especificidades contextuais e históricas de cada comunidade envolvida revelam interesses e movimentos obscurecidos pelo discurso das políticas desenvolvimentistas.

Dito posto, as falas e a vivência junto com a comunidade corroboram o papel social do PBF como elemento de seguridade social para uma parcela da população cujo trabalho caracteriza-se pela ausência de proteção social, por sua total vulnerabilidade socioeconômica Ademais, percebe-se também que esse benefício por si só não é nem capaz nem suficiente de romper com a pobreza, considerando o seu caráter isolada e desarticulado, em termos de transversalidade das políticas públicas.

Há dois posicionamentos defendidos por alguns autores quanto ao benefício pago pelo PBF. O primeiro, com uma visão mais positiva, defendido por Paiva, Falcão e Bartholo (2013) que o considera como um reconhecimento da pobreza como um problema social, já que se destina a pessoas com capacidade produtiva mas que não tem condições de renda para participar de um sistema de proteção social contributivo, necessitando, assim, de um sistema redistributivo.

O segundo, mais crítico, é defendido por Boschetti (2009), ao afirmar que, na situação contemporânea, os benefícios assistenciais, sob a forma de programas de transferência de renda permanentes, passam a ter um papel de "substitutos" dos rendimentos dos empregos inexistentes. Segundo essa visão, esse tipo de programaagudiza a histórica tensão entre trabalho e assistência social, pois é a ausência de trabalho/emprego que provoca a demanda pela expansão da assistência, sem que essa seja capaz de resolver a questão do "direito ao trabalho" e o direito a ter direitos, nos marcos do capitalismo. Assim, a assistência social não pode e não deve substituir o trabalho, mas pode ser um elemento intrínseco de um sistema maior de proteção social, complementar aos direitos do trabalho, podendo contribuir para transferir renda do capital para o trabalho.

Para Soares e Sátyro (2009) há posições que defendem que a pobreza é causada quer por problemas estruturais da própria economia e sociedade do país, quer por características das famílias que as políticas públicas não são capazes de mudar, pelo menos no curto prazo. Exemplo da primeira visão seria um padrão de inserção subordinada da economia do país na economia global, ou um padrão de desenvolvimento regional que condena certas áreas ao atraso. Exemplo da segunda seria sustentar que às famílias faltam capital social, capital humano ou redes sociais para uma boa inserção no mercado de trabalho. A consequência de qualquer destas visões é admitir que a busca por portas de saída é uma tarefa sem chances de sucesso em grande escala.

No entanto, para os autores, a posição do governo brasileiro é rejeitar a busca pelas portas de saída, mas ao mesmo tempo deixar a porta entreaberta para políticas sociais que busquem auxiliar as famílias beneficiárias a saírem da condição de pobreza. Isto se faz mediante os programas complementares, que focalizam, nas famílias beneficiárias do PBF, políticas de treinamento, de microcrédito ou de outros tipos ( por exemplo, Programa Mais Educação (PME), Programa Saúde na Escola, Programa Nacional de Acesso ao Ensino Técnico e Emprego - PRONATEC). Embora nenhum destes programas tenha sido desenvolvido explicitamente para os beneficiários do Bolsa Família, todos usam o Cadastro Único para dar algum tipo de tratamento preferencial, seja aos beneficiários do PBF, seja aos inscritos no Cadastro em geral.

Assim, muitos são os elementos que essa pesquisa gerou para se discutir o papel político que o Programa Bolsa Família tem desempenhado enquanto política pública de transferência de renda. Compreendê-lo para além do discurso é tarefa complexa e que requer metodologias que vão além dos grandes números e busquem conhecer em profundidade a vida e o trabalho dessas pessoas. Na seção seguinte, são apresentados algumas considerações finais e reflexões com vistas a pesquisas futuras sobre o objeto.

\section{Considerações Finais}

A conversa com essas mulheres contaram muito. É preciso reconhecer que as entrevistas com as beneficiárias 
fizeram estabelecer uma relação próxima, em cujas falas, foi possível extrair um panorama de explicações e relações que antes não eram tão claras. Para algumas beneficiárias a sensação de insegurança é ocasionada pela falta de oportunidade de trabalho no município. Para elas, apesar do investimento elevado para a construção do Complexo Portuário de Suape, com o discurso de ser possível gerar milhares de emprego, boa parte da população residente no município do Cabo de Santo Agostinho está desempregada e/ou perderam vagas nestas empresas para muitas outras pessoas que migraram de sua região, cidade, para o estado de Pernambuco. Disso depreende-se que houve de um lado crescimento econômico, através de maior circulação de dinheiro, mas por outro, não parecem as famílias locais terem acesso a estes postos de trabalhos criados.

Ao gerar emprego para milhares de pessoas, independentemente de ser ou não do município ou do estado, foi possível movimentar mais a economia local, porém, não se pode afirmar que houve desenvolvimento social, tendo em que foi possível ver na localidade várias famílias desempregadas, em situação de trabalhos precários, ou como no caso específico, dependente de um programa social, como o Programa Bolsa Família.

A busca em responder o alcance das Funções Políticas propostas pelo PBF junto aos seus beneficiários, partiu do pressuposto discutido por alguns autores, como por exemplo Sitcovsky (2010), que a pobreza cresce em decorrência da lógica capitalista e da precarização do trabalho e que fatores são mediações para o desenvolvimento de programas sociais de renda mínima como o Bolsa Família. Compreendeu-se que a relação de programas de transferência de renda é inerente a discussão de precarização do trabalho e que de certa forma, no caso do Brasil, o Programa Bolsa Família pareceu exercer algumas funções políticas.

Estando a grande maioria das entrevistadas inserida no contexto de precarização de trabalho, uma vez que todas estão fora do mercado de trabalho formal, observou-se que as únicas possibilidades de geração de renda que conseguem ter acesso nesse contexto, são por meio de realização de trabalhos esporádicos (faxinas, confecção e artesanato). Assim, é possível inferir que, o PBF exerce função política no sentido de permitir que estas famílias em alguns casos possam abdicar de trabalhos precários, degradantes já que elas podem considerar no momento o benefício do PBF como uma renda regular. Isto não quer dizer que estas mesmas famílias estejam acomodadas ou não queiram trabalhar. Como foi visto durante as análises, todas expuseram seu desejo em conseguir trabalhar formalmente para assim não precisar depender de um benefício, que embora seja importante para as famílias, mostrou-se insuficiente para atender às necessidade básicas.

A partir das análises conclui-se também que o PBF pode ser um amenizador de muitas das situações de insegurança, seja irregularidade no trabalho, impossibilidade de trabalhar por questões de saúde. No entanto, percebe-se que o PBF sozinho não é capaz de romper as barreiras criadas pela pobreza na localidade. A baixa escolaridade, a dificuldade que a maioria das mães encontram para deixar seus filhos em casa e poder sair para trabalhar, a falta de oportunidade de trabalho na localidade são fatores que influenciam diretamente a ausência destas mulheres no mercado de trabalho formal, o que não se pode considerar que o PBF é o principal causador por elas estarem, hoje, à margem do mercado de trabalho brasileiro. Mas, no contexto específico, pode-se considerar o que o programa é um importante auxílio para estas famílias.

Outro aspecto referente ao alcance das funções políticas exercidas pelo PBF relaciona-se com a realidade atual do lócus de pesquisa, a UDH Ponte dos Carvalhos. Como discutido anteriormente, apesar do grande investimento para a construção do Complexo Portuário de Suape, cujo objetivo declarado foi gerar emprego e renda na região, o que se vê hoje pela localidade é um grande número de pessoas desempregadas. Tanto perderam espaço para pessoas que migraram de outras regiões, quanto foram diretamente afetados pelo novo processo produtivo discutido durante todo o trabalho, ou seja, afetados pela flexibilização do trabalho. Diante disso, desta falta de oportunidade de inserir-se no mercado de trabalho formal, fica evidente a importância do benefício pago pelo PBF a diversas famílias desta localidade, em especial, às famílias participantes da pesquisa.

Finalmente, cabe reforçar a relevância de discussões e investigações científicas sobre o PBF, sobretudo com abordagens de pesquisa qualitativas, que tirem dos grandes números as realidade dos fatos e façam emergir um diagnóstico qualificado e alinhado com os propósitos sociais de uma política pública desta natureza.

\section{Referências}

ALVES, G. Trabalho e Neodesenvolvimentismo: choque de capitalismo e nova ideologia do trabalho no Brasil. Bauru, Canal 6, 2014.

Trabalho e subjetividade: o espírito do toyotismo na era do capitalismo manipulatório. São Paulo: Boitempo Editorial, 2011.

Dimensões da Estruturação Produtiva: ensaios da sociologia do trabalho. $2^{\mathrm{a}}$ edição. Londrina: Praxis; Bauru: Canal 6, 2007. 
DENZIN, N. K.; LINCOLN, Y. S. Paradigmatic controversies, contradictions, and emerging confluences. In: DENZIN, N. K.; LINCOLN, Y. S. (Eds) The Sage Handbook of qualitative research. 3.ed. Thousand Oaks: SagePublications, 2005.

HARVEY, David. Condição Pós-moderna: Uma pesquisa sobre as origens da mudança cultural. 24. ed. São Paulo: Edições Loyola, 1992.

GODOI, C.K; MATTOS, P. L. C. L. Entrevista qualitativa: instrumento de pesquisa e evento dialógico. In: GODOI, C.K; BANDEIRA-DE-MELLO, R; SILVA, A. B. (Orgs) Pesquisa qualitativa em estudos organizacionais. São Paulo: Saraiva, 2006.

GODOY, A. S. A pesquisa qualitativa: tipos fundamentais. Revista de Administração de Empresas, São Paulo, v. 35, n. 3, p. 20-29, maio/jun. 1995.

GODOY, A. S. Refletindo sobre critérios de qualidade da pesquisa qualitativa. Revista Eletrônica de Gestão Organizacional, v. 3, n. 2, mai/ago, 2005

MATTEI, L. Políticas Sociais de Combate à Pobreza no Brasil. 2015. Disponível em: http://www.brasa.org/wordpress/wp-content/uploads/2015/07/Lauro-Mattei.pdf.

MOTA, A. E.; AMARAL, A.; PERUZZO, J. O novo desenvolvimentismo e as políticas sociais na América Latina. In: MOTA, A. E. (Org.) Desenvolvimentismo e construção de hegemonia: crescimento econômico e reprodução da desigualdade. São Paulo: Cortez Editora, 2012, p. 153-178.

SILVA, M. O. S e. O Bolsa Família: problematizando questões centrais na política de transferência de renda no Brasil. Ciênc. Saúde Coletiva, Rio de Janeiro, v. 12, n. 6, 2007

SILVA, M. O. S; YAZBEK, M.G; GIOVANNI, Gi. A Política Social Brasileira no século XXI: A prevalência dos programas de transferência de renda. 5 ed. São Paulo: Cortez, 2011

SITCOVSKY, M. Bolsa Família e reprodução da força de trabalho no Brasil: implicações socioeconômicas e políticas. Tese (Doutorado em Serviço Social). Universidade Federal de Pernambuco, 2010.

POCHMANN, M. Debates contemporâneos, economia social e do trabalho: a superterceirização do trabalho. São Paulo: LTr, 2008. 